Seção: Teorias e Práticas Pedagógicas - Ensaio dissertativo

\title{
ENSINO DE BIOLOGIA PARA A EDUCAÇÃO DE JOVENS E ADULTOS - DESAFIOS PARA UMA FORMAÇÃO QUE PROPORCIONE O DESENVOLVIMENTO HUMANO
}

\author{
TEACHING BIOLOGY TO YOUTH AND ADULT EDUCATION - CHALLENGES \\ OF A TRAINING TOWARDS HUMAN DEVELOPMENT
}

\section{ENSEÑANZA DE BIOLOGÍA PARA LA EDUCACIÓN DE JÓVENES Y ADULTOS - DESAFÍOS PARA UNA FORMACIÓN QUE PROPORCIONE EL DESARROLLO HUMANO}

\author{
Rones de Deus Paranhos \\ Titulação do autor: Doutor em Educação (UnB) \\ Instituição: Universidade Federal de Goiás, Instituto de Ciências Biológicas \\ E-mail: paranhos@ufg.br

\section{Maria Helena da Silva Carneiro} \\ Titulação do autor: Doutora em Didática das Disciplinas: Biologia (Paris VII) \\ Instituição: Universidade de Brasília, Faculdade de Educação \\ E-mail:mhsilcar@unb.br
}

\section{RESUMO}

Este ensaio objetiva estabelecer um paralelo entre as características da educação escolar na sociedade capitalista com as características do público da Educação de Jovens e Adultos (EJA) e projeto formativo em seu atual formato, localizando o ensino de biologia nas contradições levantadas. $\mathrm{O}$ formato da educação de adultos na história da educação brasileira não representa uma constante, pois sua organização e modos de oferecimento estiveram ligados a diferentes contextos político-econômicos do Brasil. Quando tomada a educação de adultos na relação com a instituição escola, há de se considerar ainda que a educação escolar na sociedade capitalista se constituiu num campo de disputa, pois ela materializa os interesses de classe, reproduzindo assim, as relações sociais de produção. Contudo, por meio de suas contradições, a escola representa para o público da EJA a possibilidade de desenvolvimento humano via a aprendizagem dos conhecimentos (artísticos, científicos, estéticos e filosóficos) historicamente produzidos. Com essas premissas, defende-se que ensinar biologia na EJA pressupõe compreender que essa atividade se dá numa escola que está alinhada aos interesses do modo de produção. $\mathrm{O}$ ensino de biologia que se processa na escola de jovens e adultos trabalhadores demanda, ter no horizonte, o desenvolvimento de um trabalho pedagógico que considere essas mediações, pois do contrário, esse ensino continuará corroborando com os processos de marginalização reiterada e institucionalizada pelos quais os educandos da EJA têm sido submetidos.

Palavras-chave: Educação Escolar. EJA. Ensino de Biologia.

\footnotetext{
ABSTRACT

This essay aims at establishing a parallel between the characteristics of school education in the capitalist society, the Youth and Adult Education (EJA) and the current formative project,
} 
Seção: Teorias e Práticas Pedagógicas - Ensaio dissertativo

positioning the teaching of Biology in the contradictions identified. The format of EJA in the history of Brazilian education is dynamic because its organization and ways of offering it were tied to different political and economic contexts in Brazil. When talking about EJA within schools, it should be considered that school education in the capitalist society has always been constituted as a field of dispute, since it materializes class interests, thus, reproducing the social relations of production. Despite all its contradictions, to EJA students, the school represents the possibility of human development through the learning of historically produced knowledge (artistic, scientific, aesthetic, and philosophical). With these premises in mind, it is argued that the teaching of Biology to EJA students presupposes understanding that this activity takes place in a school that is aligned with the interests of the mode of production. The teaching of Biology that takes place in schools for young and adult workers demands the development of a pedagogical work that considers those mediations. Otherwise, it will corroborate the institutionalized processes of marginalization through which EJA students have been submitted.

Keywords: School Education. EJA. Teaching of Biology.

\section{RESUMEN}

Este ensayo pretende establecer un paralelismo entre las características de la educación escolar en la sociedad capitalista con las características del público de la educación juvenil y adulta (EJA) y su diseño formativo en el formato actual, localizando la enseñanza de la biología en las contradicciones identificadas. El formato de la educación de adultos en la historia de la educación brasileña no es constante, porque su organización y modos de oferta siempre estuvieron vinculados a diferentes contextos políticos y económicos en Brasil. Cuando se toma la educación de adultos en relación con la institución escolar, tendrá que considerarse que la educación escolar en la sociedad capitalista se constituyó en un campo de disputa, porque materializa los intereses de clase, reproduciendo así las relaciones de producción social. Sin embargo, a través de sus contradicciones, la escuela representa para el público de la EJA la posibilidad de desarrollo humano a través del aprendizaje del conocimiento (artístico, científico, estético y filosófico) producido históricamente. Con estas hipótesis, se argumenta que la enseñanza de la biología en la EJA presupone entender que esta actividad se produce en una escuela que está alineada con los intereses del modo de producción. La enseñanza de la biología que se procesa en la escuela de trabajadores jóvenes y adultos exige, tener en el horizonte, el desarrollo de un trabajo pedagógico que considere estas mediaciones, porque de lo contrario, esta enseñanza seguirá corroborando con los procesos de marginación reiterada e institucionalizada por los cuales los estudiantes de la EJA han sido sometidos.

Palabras-clave: Educación escolar. EJA. Enseñanza de Biología.

\section{INTRODUÇÃO}

Este texto discute o ensino de biologia para a modalidade Educação de Jovens e Adultos (EJA), no sentido de problematizar a natureza da especificidade do ensino do conhecimento biológico para os educandos da EJA. Trata-se de um ensaio teórico que explicita em sua discussão a necessidade do desenvolvimento de um compromisso político para guiar o ensino de biologia na modalidade, tendo no horizonte desse compromisso, a concepção de educação 
como direito. Para tanto, o texto traz como determinações desse ensino três pontos, a saber: a) educação escolar e seu projeto formativo; b) concepção de EJA e seus sujeitos; c) demarcação das intencionalidades formativas do ensino de biologia.

A partir dessas determinações, o texto defende que ensinar biologia na EJA passa por compreender as contradições presentes entre uma formação que promove o desenvolvimento dos educandos e o projeto formativo da atual escola. Ao passo que se compreende essas contradições, esse ensino não corrobora a marginalização reiterada e institucionalizada dos educandos que retomam ou iniciam o processo de escolarização. A especificidade do ensino de biologia não reside na centralidade dada às adaptações metodológicas de ensino vindas das etapas do Ensino Fundamental e Médio, pois em sua essência, a especificidade é políticopedagógica e requer não dissociar conteúdo-forma. Para a EJA fica salientada a demanda do ensino de biologia estar orientado politicamente à classe trabalhadora com vistas a proporcionar aos educandos a possibilidade de desenvolvimento humano ao se apropriarem dos conceitos científicos historicamente produzidos. Para compreender as determinações que sustentam essa ideia, os tópicos a seguir se ocupam delas.

\section{A EDUCAÇÃO ESCOLAR NA SOCIEDADE CAPITALISTA}

A análise da educação tem que se dar não de modo abstrato, pois por se tratar de uma dimensão da vida dos homens, "se modifica historicamente, acompanhando e articulando-se às transformações do modo pelo qual os homens produzem a sua existência." (LOMBARDI, 2011, p.236). Soma-se a esse posicionamento, a leitura de Rossi (1978), que orienta a não realizar análises genéricas sobre a educação como se esta fosse oferecida em condição de igualdade para todos. Este ensaio apresenta aspectos que auxiliam pensar sobre as mediações presentes entre a instituição escolar e o modo de produção, evidenciando assim, características de um projeto formativo escolar com o qual o público da EJA se depara. Para tal, considerou-se as leituras que discutem o modo produtivo capitalista e a educação (ENGUITA, 1989; FRIGOTTO, 2010a; 2010b; LOMBARDI, 2011; MÉSZÁROS, 2008).

A formação que a escola pode proporcionar às pessoas jovens e adultas não se desvincula das determinações presentes na configuração da atual educação escolar em que se pode destacar as mediações com o modo de produção vigente. Analisar o ensino de biologia na EJA supõe considerar a instituição (escola) em que se processa esse ensino. A escola, por seu turno, está inserida numa realidade concreta, estabelecendo mediações com aspectos dessa realidade, dentre eles, o modo de produção capitalista. Portanto, neste ensaio, a mediação 
(capitalismo - educação) foi tomada para que se delineasse uma discussão em torno do ensino de biologia na EJA.

A compreensão sobre mediação de que se lança mão neste escrito está alinhada à discussão de Cury (2000). Esse autor define a mediação como um conjunto de relações dialéticas existentes entre as partes e o todo, portanto, a análise do ensino de biologia na EJA não deve se dar fechado nele mesmo. Esse ensino se dá na relação com outros aspectos do fenômeno da educação institucionalizada (escola, conteúdo-forma, projeto formativo, modo de produção) e aqui, buscou-se compreender as mediações entre o ensino do conhecimento biológico praticado na EJA e a escola. Considerar a categoria mediação justifica-se por não dicotomizar os processos que estão presentes na realidade, gerando assim, retalhos que se desprendem da totalidade, minando o seu movimento e sua historicidade. A partir dessa acepção e pelo conjunto de autores empregados neste ensaio é possível compreender que no engendramento e consolidação da sociedade capitalista, a educação foi um dos meios para propagandear o ideário liberal burguês (Hobsbawm, 2015a; 2015b), além de se instituir nela um projeto formativo para a classe trabalhadora bem distinto daquele endereçado à burguesia.

Frigotto (2010a, p.87) diz que há estabelecimento de relações sociais entre os homens para a produção de sua existência e isso configura as relações de produção. Estas por seu turno, em companhia da capacidade de produzir (forças produtivas) constituem o "modo de produção que nos fornece o método para caracterizar as sociedades e analisar suas transformações". O modo de produção, de acordo com o autor, é uma categoria básica para se compreender a maneira pela qual os homens produziram sua existência e como as relações sociais que se desdobraram desse aspecto ao longo da história. O modo de produção subordina outros aspectos da vida social (MARX, 2012). Os homens ao produzirem a própria existência,

[...] contraem relações determinadas, necessárias e independentes de sua vontade, relações de produção estas que correspondem a uma etapa determinada de desenvolvimento das suas forças produtivas materiais. A totalidade dessas relações de produção forma a estrutura econômica da sociedade, a base real sobre a qual se levanta uma superestrutura jurídica e política, e à qual correspondem formas sociais determinadas de consciência. $\mathrm{O}$ modo de produção da vida material condiciona o processo em geral da vida social, político e espiritual (MARX, 2012, p.270-271).

A partir dessa passagem de Marx, entende-se que a organização da atual escola não se dá de forma independente do modo de produção, configurando-se uma relação mediata. A existência da escola não é imediata e sua materialidade é resultado de múltiplas determinações. A escola atual reproduz as relações sociais de produção para a manutenção do ideário da classe dominante. Portanto, a categoria mediação é capital em análises que se debruçam sobre a escola 
Seção: Teorias e Práticas Pedagógicas - Ensaio dissertativo

da sociedade capitalista, pois por meio dessa categoria, apreende-se as contradições postas no projeto formativo da escola capitalista.

A educação escolar na sociedade capitalista pode ser entendida como a que é geradora de consensos (LOMBARDI, 2011; MÉSZÁROS, 2008). Para dar sustentação a essa afirmação é necessário compreender a presença da escola no período de transição - com suas rupturas e permanências - entre o feudalismo e capitalismo, contextualmente marcado pelo ideário da liberdade, constituição de Estado-Nação, direito à propriedade e estabelecimento de novos mecanismos produtivos que marcaram uma diferença entre os que detinham os meios de produção e os que podiam vender sua força de trabalho.

Em “Educação e ensino na obra de Marx e Engels", Lombardi (2011) realiza uma análise dos fundamentos da educação presente nos escritos de Marx e Engels, evidenciando uma concepção de educação e ensino em que o fundamento é o trabalho. No conjunto dessa obra o autor vai apresentando elementos circunstanciais à obra marxiana e pondo em relevo a relação entre educação e ordem econômica que se instalou com o capitalismo.

A educação na sociedade capitalista, de acordo com Lombardi (2011), se reveste de contradição porque seu projeto formativo está alicerçado na geração de conformidades, porém, nas atuais condições históricas, é a via de formação política em que a classe trabalhadora pode ter acesso aos conhecimentos científicos. Esse acesso, por sua vez, potencialmente garantiria o controle do "processo de produção e reprodução dos conhecimentos científicos e técnicos envolvidos no processo produtivo" (p.106). Porém, ao invés de ser uma alavanca de transformação, a educação na sociedade capitalista se tornou um mecanismo do próprio capitalismo para fornecer aparatos ideológicos que apregoam consensos que mascaram a desigualdade, reforçando, a exemplo, a ideia de que "todos são iguais diante da lei" (MÉSZÁROS, 2008, p.16). Nessa direção, conforme Lombardi (2011, p.116), a educação foi se configurando um elemento de internalização do ideário burguês que instrumentalizou a "mudança ideológica e comportamental, pela qual os trabalhadores eram levados à aceitação e naturalização das normas, padrões e valores da sociedade capitalista".

Lombardi (2011, p.239) sinaliza a necessidade de romper com as pedagogias que estão articuladas com os interesses burgueses com vistas a um vínculo a uma concepção de homem e de mundo, em que o educador possa exprimir isso em suas concepções e práticas. Ainda para o autor, tal vínculo não se restringe à aderência a uma concepção científica de mundo com seu poder de compreender a realidade, "mas de assumir, na teoria e na prática, isto é, na práxis, uma concepção transformadora da vida, do homem e do mundo". A dimensão política se faz presente nas considerações do autor quando diz 
Seção: Teorias e Práticas Pedagógicas - Ensaio dissertativo

[...] em lugar de uma escola onde "professores fingem que ensinam" para "alunos que fingem que aprendem", centrada na forma e não no conteúdo, é preciso propiciar a todos o acesso aos conhecimentos historicamente produzidos pela humanidade, bem como uma educação crítica, voltada ao atendimento de toda a sociedade, dentro de uma perspectiva política de transformação social (LOMBARDI, 2011, p.240).

Em a "Face oculta da escola: educação e trabalho no capitalismo", Mariano Enguita, por meio de uma retomada histórico-analítica, apresenta ao leitor o processo de reconfiguração da instituição escolar na sociedade do capital. Na obra, Enguita (1989, p.130-131) demarca o entendimento que o processo educativo estava posto antes mesmo da consolidação do capitalismo, contudo, na relação com esse sistema, a educação e as instituições escolares se recriaram, onde as necessidades "em termos de mão de obra foram o fator mais poderoso a influir mudanças ocorridas no sistema escolar em seu conjunto e entre as quatro paredes da escola".

No engendramento da sociedade capitalista, considerando as duas grandes revoluções (Industrial e Francesa) como determinantes disso, Hobsbawm (2014) afirma que a industrialização demandou do trabalhador um "aprender a trabalhar" em conformidade com a organização da indústria o que incluía regularização de ritmos, responder a incentivos monetários e assujeitamentos à disciplina fabril. Para Enguita (1989, p.221), a industrialização gerou a necessidade histórica de substituir "as atitudes e os valores para a sociedade agrária por outros adequados para sociedade industrial" e, além disso, inculcar nos trabalhadores a aceitação de se trabalhar para o outro em concordância com as condições deste. Esse autor ainda afirma que

\footnotetext{
Se os meios para dobrar os adultos iam ser a fome, o internamento ou a força, a infância (os adultos das gerações seguintes) oferecia vantagem de poder ser modelada desde o princípio de acordo com as necessidades da nova ordem capitalista industrial, com as novas relações de produção e os novos processos de trabalho (ENGUITA, 1989, p.113).
}

Portanto, a relação entre burguesia e proletariado ressoou na educação, de modo a proporcionar ajustamentos para que a "harmonia" social fosse garantida frente às diferenças de classes. $\mathrm{Na}$ escola que se recriara, tida como lócus da disciplina e formadora de submissões, a preocupação formativa não estava focada nos conhecimentos a serem ensinados. Enguita (1989) afirma que a pauta primeira era desarraigar os trabalhadores de determinados hábitos, tido como irregulares, nas suas relações com o trabalho. Esse mesmo autor evidencia a reprodução das relações de produção capitalista no ambiente escolar, na medida em que há determinação de fins por uma vontade alheia, pois o que deve ser aprendido (conteúdo do ensino-aprendizagem) 
Seção: Teorias e Práticas Pedagógicas - Ensaio dissertativo

é estranho a quem aprende, ou seja, a alienação é transposta para as relações que se processam na escola. Para o autor, nessa perspectiva

É o professor, livremente ou sob restrições, quem decide se a aprendizagem será baseada na memória ou "ativa", se as borboletas serão estudadas ao vivo ou na página 53 do livro artificial de ciências naturais, se os alunos podem cooperar na realização de seu trabalho ou devem competir ferozmente entre si, se o importante é saber localizar uma banana na classificação dos vegetais ou conhecer suas qualidades nutritivas, etc. (ENGUITA, 1989, p.173).

Outro aspecto destacado por Enguita (1989, p.194) diz respeito às motivações postas para a escola da sociedade capitalista que se dão mediante a recompensas extrínsecas, reproduzindo assim, a lógica das relações de produção. Na escola, essas motivações se materializam pela “aprovação social, oportunidades de promoção acadêmica, oportunidades ocupacionais e sociais, possibilidades de evitar sanções". O papel social da escola acaba se revestindo de aspectos ideológicos que atribuem a ela a promessa da mobilidade social aos desprovidos de uma posição social desejável.

Na obra intitulada "A educação para além do capital”, de István Mészáros, o leitor é levado a entender que o projeto formativo da educação, a que ele chama de institucionalizada, não se restringe em apenas fornecer aos trabalhadores conhecimentos necessários para lidar com as máquinas e expandir o sistema capitalista. Na pauta formativa dessa educação está todo um conjunto de valores que ratifica os interesses da classe dominante, ofuscando qualquer alternativa de gestão da sociedade (MÉSZÁROS, 2008). O autor chama de "internalização" os processos que a educação e a escola lançam mão para que os indivíduos tenham como suas, as metas de reprodução dos valores capitalistas. Porém, Mészáros, numa passagem do seu livro, deixa claro que a instituição escolar e a educação que se pratica nela é apenas um dos componentes desses processos de internalização, quando diz:

\begin{abstract}
As instituições formais de educação certamente são uma parte importante do sistema global de internalização. Mas apenas uma parte. Quer os indivíduos participem ou não - por mais ou menos tempo, mas sempre em um número de anos bastante limitado das instituições formais de educação, eles devem ser induzidos a uma aceitação ativa (mais ou menos resignada) dos princípios reprodutivos orientadores dominantes na própria sociedade, adequados a sua posição na ordem social, e de acordo com as tarefas reprodutivas que lhes foram atribuídas (MÉSZÁROS, 2008, p.44).
\end{abstract}

Mészáros (2008, p.45) reitera que a educação formal, veículo de internalização dos valores capitalistas, tem como uma de suas funções principais produzir "tanta conformidade ou "consensos" quanto for capaz, a partir de dentro e por meio dos seus próprios limites institucionalizados e legalmente sancionados". O autor marca a necessidade de se engendrar 
Seção: Teorias e Práticas Pedagógicas - Ensaio dissertativo

atividades de "contrainternalização" que não fiquem reduzidos à negação, mas sim se constituir uma alternativa ao que existe, superando-o. Afirma que

[...] o papel da educação é soberano, tanto para a elaboração de estratégias apropriadas e adequadas para mudar as condições objetivas de reprodução, como para a automudança consciente dos indivíduos chamados a concretizar a criação de uma ordem social metabólica radicalmente diferente [...]. Portanto, não é surpreendente que na concepção marxista a "efetiva transcendência da autoalienação do trabalho" seja caracterizada como uma tarefa inevitavelmente educacional (MÉSZÁROS, 2008, p.65).

Na relação entre capitalismo e educação, faz-se necessário trazer à baila o conceito de capital humano como mais um elemento que delineia o projeto formativo da escola capitalista. Possivelmente, esse seja o conceito que mais dê conta da contradição que se instala entre as demandas dos educandos da EJA na busca da escola e o projeto de formação que essa oferece a eles. Em a "Produtividade da escola improdutiva" (FRIGOTTO, 2010a) é apresentada uma análise sobre a origem e desenvolvimento do conceito de capital humano, basilar para se compreender a atual escola e sua relação com o modo produtivo. Já em Educação e a crise do capitalismo real (FRIGOTTO, 2010b), o autor retoma a discussão do capital humano em tempos neoliberais.

De acordo com Frigotto (2010a), a teoria do capital humano tem como um de seus representantes pioneiros T. Schultz, que na década de 1970, escreveu o livro chamado O Capital Humano. Frigotto (2010a) discute que os partidários desse conceito o utilizam para explicar o desenvolvimento econômico em países mais desenvolvidos. A discussão em torno do conceito de capital humano diz que os investimentos feitos em indivíduos geram expectativas de retornos econômicos. Em termos macroeconômicos resulta desenvolvimento e produtividade e nos aspectos microeconômicos o capital humano dá conta de explicar as diferenças de renda e inculca nos sujeitos a mobilidade social via um investimento formativo, já que esse sujeito, em termos produtivos, é resultado da combinação entre trabalho físico e treinamento.

Nessa lógica, a educação, então, é o principal capital humano concebida como produtora de capacidade de trabalho, potenciadora do fator trabalho. Nesse sentido é um investimento como qualquer outro. O processo educativo, escolar ou não, é reduzido à função de produzir um conjunto de habilidades intelectuais, desenvolvimento de determinadas atitudes, transmissão de um determinado volume de conhecimentos que funcionam como geradores de capacidade de trabalho e, consequentemente, de produção (FRIGOTTO, 2010a, p.51).

O conceito de capital humano mascara ideologicamente a tensão existente nas relações de produção. As diferenças de classes, a força de trabalho como mercadoria a ser comprada, sendo o preço determinado por fatores externos ao trabalhador são, na lógica do capital humano, 
Seção: Teorias e Práticas Pedagógicas - Ensaio dissertativo

atenuados pela ideologia de que é o trabalhador o responsável pelas suas condições sociais. “A definição de renda, nesse raciocínio, é uma decisão individual. Se passa fome, a decisão é dele (indivíduo); se fica rico, também" (FRIGOTTO, 2010a, p.61). Instalam-se explicações meritocráticas para a realidade social que perpassa a diferença de classes em que a desigualdade social se explica pela qualificação dos sujeitos que constituem as classes sociais.

A educação sob os ditames do capital humano engendra um projeto formativo para os sujeitos que saneia da prática educativa a perspectiva política, social e filosófica dado que ela se reduz a um elemento do cenário econômico, um elemento da produção (FRIGOTTO, 2010a). $\mathrm{O}$ autor ainda destaca que o traço marcadamente político e social do ato educativo se reduz a "uma tecnologia educacional" que se coloca a serviço da vigente organização social.

A sociedade, na lógica do capital humano, é a do conhecimento e cabe ao homem se apropriar dos conhecimentos necessários a garantir o status de competitividade para vender sua força de trabalho em concordância com a agenda econômica. A ordem mercadológica forja o projeto formativo da escola a partir de conceitos/categorias como: flexibilidade, participação, trabalho em equipe, competência, competitividade e qualidade total (FRIGOTTO, 2010b). Para o autor, essas categorias representam a versão do capital humano rejuvenescida pelo neoliberalismo em que os mentores são o Banco Mundial, BID (Banco Interamericano de Desenvolvimento), UNESCO e OIT (Organização Internacional do Trabalho). A educação escolar alinhada aos interesses da classe trabalhadora constitui-se num instrumento de organização e consciência (FRIGOTTO, 2010a).

\section{EDUCAÇÃO DE JOVENS E ADULTOS: CONCEPÇÕES, SUJEITOS E ASPECTOS POLÍTICOS}

A configuração da modalidade da Educação Básica denominada Educação de Jovens e Adultos (EJA) se dá na/pela luta do reconhecimento da necessidade histórica de escolarizar pessoas que foram marginalizadas do direito à educação. Aqui entende-se que esse processo de marginalização abarca as pessoas não alfabetizadas e as que não concluíram seus estudos nas etapas do Ensino Fundamental e Médio. Há um quantitativo considerável de brasileiros que potencialmente adentrariam as escolas da EJA.

A começar pelos não alfabetizados, o Brasil ainda contém um índice significativo de pessoas que não apresentam o domínio da leitura e da escrita, o que totaliza 13,2 milhões de pessoas. Os dados do analfabetismo no Brasil indicam que o ano de 1900 apresentava uma taxa equivalente a $65 \%$ da população (6.348.000), quando que em 2006 essa taxa ficou na casa dos 10,4\% (14.391.000) (SARTORI, 2011), tendo caído o número percentual, mas não o real. 
Soma-se a esse quantitativo os $64 \%$ de brasileiros que não concluíram a Educação Básica. São essas pessoas, não escolarizadas ou com baixa escolarização que constituem uma "multidão de invisíveis" potencialmente público da EJA (ALVES et al., 2014).

A história da educação de jovens e adultos possui mais tensões do que a trajetória histórica da educação básica (ARROYO, 2005). Esse autor sustenta sua afirmação justificando que no processo de engendramento da EJA há mais dissensos do que consensos quando comparada com a educação da infância e da adolescência. $O$ autor vincula essa situação menos consensual às condições do lugar social que o público dessa modalidade ocupa, por serem

[...] trabalhadores, pobres, negros, subempregados, oprimidos, excluídos. [...] A história oficial da EJA se confunde com a história do lugar social reservado aos setores populares. É uma modalidade do trato dado pelas elites aos adultos populares (ARROYO, 2005, p.221).

No movimento que envolve o engendramento das concepções de EJA é possível notar elementos de permanência ligados às formas de organização dessa modalidade ainda atrelada aos moldes da suplência que se assenta numa ideia de formação aligeirada e correção da distorção idade/série.

Sartori (2011) aponta que esses elementos de permanência obstaculizam os processos de pensar a EJA para além desse modelo posto ainda nos idos de 1970. O mesmo autor ainda considera que falta desconstruir algumas ideias que perpassam a EJA, seja no campo legal e/ou pedagógico, dentre elas, a de uma educação compensatória calcada na ideia da suplência, dos alunos como clientela a ser atendida em lugar de sujeitos de direito. $\mathrm{O}$ autor salienta que esses são elementos que ainda necessitam ser rompidos com vistas à constituição da EJA enquanto espaço que atenda as especificidades de seu público.

A concepção de EJA entendida como momento de recuperação de um tempo perdido, marca um tempo ideal para aprender (infância e adolescência). De acordo com Souto (2011), Esse aspecto necessita ser ressignificado, pois é tributário da concepção de ensino supletivo e de uma organização curricular que reduz os conteúdos a serem ensinados aos jovens e adultos, tendo como referência os que são ensinados no ensino fundamental e médio.

No campo discursivo, a palavra regular é frequentemente empregada para se referir às etapas fundamental e média que não o da modalidade EJA ou quando se quer marcar as diferenças da educação de jovens e adultos em relação ao ensino dito "regular" (Ensino Fundamental e Médio). Sartori (2011, p.58) salienta que isso se trata de uma herança da Lei 5.692/71 e faz a observação que a EJA "é tão regular como o ensino ministrado às crianças e adolescentes que estão na idade considerada como "correta" na relação idade/série". Porém, ao 
definir EJA, esse autor afirma que é uma "modalidade de ensino dentro da Educação Básica" (p.58).

Há necessidade de revisitar essa definição, na medida em que ela pode acarretar reducionismos para a educação de jovens e adultos. A EJA é uma modalidade de Educação por apresentar um rol de especificidades que se vinculam essencialmente ao seu público. $\mathrm{Na}$ discussão da EJA, na formulação e implementação de políticas públicas para a modalidade há de se considerar as dimensões das concepções de EJA, intersetorialidade, controle social, formação de professores(as), aspectos didático-pedagógicos, gestão pública e dados da EJA (CONAE, 2010, p.150). Isso é, não se trata apenas de aspectos ligados ao ensino dos componentes curriculares na EJA.

Sartori (2011, p.66) destaca que na atualidade a concepção de EJA se assenta na busca por "metodologias que não venham novamente repetir o processo de fracasso, muito menos, formas aligeiradas de reprodução e adequação de conteúdos trabalhados no ensino fundamental ou médio [...]". Embora essa busca seja necessária, mais urgente ainda é não se restringir a ela, pois a EJA, mais que metodologias específicas, demanda um projeto formativo próprio que por sua vez requer metodologias que venham ao encontro desse projeto. Fixar-se na ideia da busca de metodologias descoladas de um projeto formativo é promover mudanças na aparência sem, contudo, mudar a essência, o que por sua vez, acaba por permitir a transposição das formas de ensinar já postas para o Ensino Fundamental e Médio. Não se trata de pensar em metodologias para um campo pedagógico específico (Educação de Jovens e Adultos), mas sim de pensar esse campo a partir de suas concepções, fundamentos e projeto formativo.

Ainda sobre as concepções de EJA, Arroyo (2005) em seu texto apresenta um alerta sobre os traços de legados que a educação popular marcou na constituição dessa modalidade de educação. Dentre os traços mencionados pelo autor, destacam-se os seguintes: a) a atualidade do legado da EJA - a atual realidade vivenciada pelos jovens e adultos ainda continua calcada na exclusão, sendo esse um princípio explicitado na década 1960, ou seja, se constitui um elemento de permanência frente aos processos reivindicatórios da EJA; b) olhar primeiro para os educandos, para sua condição humana - esse é o traço que materializa a especificidade da EJA e coloca desafios para a formulação de propostas pedagógicas para o público da modalidade.

A literatura indica a necessidade de considerar a EJA a partir da concreticidade do seu público, ou seja, para além das palavras que estão unidas no termo que dá nome à modalidade educativa. Portanto, passa por ponderar as diferentes trajetórias do público, seus pertencimentos, suas motivações pela busca da educação escolarizada, compreendendo, 
inclusive, as contradições que possam se instalar nessa busca. Portanto, há um cenário diverso de sujeitos que constituem o público da EJA e que, por sua vez, traça um rol de demandas formativas muito heterogêneas, mas que têm como pano de fundo o direito humano de acesso à educação.

A modalidade EJA, ao mesmo tempo, reúne jovens que balizam a "juvenilização", devido à marcada presença de um público pertencente à faixa etária de 15-29 anos somado aos adultos e idosos que trazem para as escolas da EJA suas trajetórias de trabalho e vida (FURINI; DURAND; SANTOS, 2011, p.173). O processo de escolarização dessas pessoas constantemente irrompe mudanças neste sujeito, na medida que se estabelece a relação entre adultos com os jovens e destes com os adultos. De acordo com os autores, esse contato pode gerar dois tipos de relacionamentos, o aproblemático e o problemático. O primeiro não explicita nenhum conflito no encontro dessas gerações; enquanto o segundo, coloca em destaque o "caráter ameaçador que os jovens podem representar aos adultos".

É necessário ter cautela com os discursos que desqualificam a presença dos jovens na modalidade, uma vez que a própria EJA é, por natureza, a possibilidade que resgata o gozo do direito à educação escolar. Há relatos que maximizam a presença do jovem na EJA enquanto um obstáculo a ser superado, um entrave para o desenvolvimento de práticas pedagógicas quando considerados sua presença na escola junto a pessoas adultas. Em Carrano (2005) encontra-se um forte argumento para esses posicionamentos repulsivos e contraditórios que perpassam a presença do jovem na EJA, pois o autor afirma que a

[...] dificuldade de lidar com a diversidade parece algo congênito na constituição da ideia de escolarização. A homogeneidade ainda é muito mais desejável à cultura escolar do que a noção de heterogeneidade, seja ela de faixa etária, de gênero, de classe, de cultura regional ou étnica (CARRANO, 2005, p.160).

Como se vê, a heterogeneidade ligada ao perfil dos educandos dá o tom das especificidades dessa modalidade de educação.

Em relação a esse aspecto, porém, não se trata apenas de especificidades relacionadas à idade, mas sim cultural (OLIVEIRA, 2005b). É possível encontrar pessoas numa faixa etária que varia entre menores de 15 anos a pessoas com mais de 60 anos de idade; quanto às questões étnico-raciais se observa pardos, pretos, brancos, indígenas e amarelos; há a predominância de um público masculino; e pertencem à classe trabalhadora (ALVES et al., 2014). Constituem também esse público os que são privados de liberdade; adolescentes abrigados ou em conflito com a lei, pessoas com deficiência, travestis, transexuais e pessoas em situação de rua (ZORZAL; MIRANDA; RODRIGUES, 2014). Catelli-Jr. e Escoura (2016) expõem o cenário 
da discriminação à população LGBT (Lésbicas, Gays, Bissexuais e Transgêneros) que se instala, inclusive no ambiente escolar, afastando travestis e transexuais da escola, reiterando nesse espaço, a reprodução de intolerâncias e desigualdades. Face a esse quadro, a EJA colocase, na perspectiva dos autores, como espaço para o reconhecimento desse público garantindo a ele o direito de acesso e permanência na escola. Como estratégia para essa garantia, sinalizam a possibilidade de aproximação entre o movimento LGBT e EJA para a construção de uma pauta conjunta com vistas à garantia de direitos.

No estudo realizado por Alves et al (2014), em que o processo de escolarização do brasileiro é o foco, eles afirmam a partir de um resgate histórico, que o direito à educação no Brasil ainda se vincula às condições de classe. Essa tese, é ilustrada pela realização de um estudo na cidade de Goiânia em que os autores constatam que o público da EJA é constituído por: a) a predominância de gênero (masculino); b) educandos de origem afrodescendentes; c) sujeitos da classe trabalhadora com uma parcela considerável que estão imersos no trabalho informal. A educação oferecida a essas pessoas demanda ser diferenciada, pois elas materializam o descaso social ligado aos seus direitos. Nessa direção, é incongruente o oferecimento de uma educação nos mesmos moldes da que é oferecida a crianças.

A EJA, pela sua natureza, coloca em xeque essa forma de pensar a organização do trabalho pedagógico no que se refere ao currículo. Os educandos da EJA já trazem consigo uma leitura de mundo que deveria ser considerada no processo da organização curricular, a ser implementada nas escolas da educação de jovens e adultos. No processo de escolarização dos sujeitos a questão que envolve o que estes devem aprender é central na atual organização curricular. Soma-se a isso a organização do tempo escolar, dos conhecimentos em disciplinas e da escolha de metodologias para que o ensino se efetive (OLIVEIRA, 2005a). Essa autora apresenta o desafio de pensar as questões curriculares da EJA sobre outra ótica, em que fosse considerado a "[...] a riqueza dos processos reais de vida social e, portanto, escolar, seria necessário desenvolver novos modos de compreensão revertendo-se a tendência dominante de entendimento do currículo." (p.236), aspecto esse que precisa ser discutido com maior ênfase no espaço educacional.

O fazer docente na sala de aula da EJA requer considerar outra questão que caminha ao lado dos aspectos pedagógico/metodológicos da modalidade educativa. Machado (2010, p.251), ao discutir o direito à educação afirma, que "A alfabetização de jovens e adultos, para além das questões metodológicas e pedagógicas, precisa ser enfrentada como problema de política pública do ensino fundamental.”. Por mais que a referência da autora seja feita ao processo de alfabetização de pessoas jovens e adultas, é possível estender essa discussão a outras etapas de 
escolarização desse público. Portanto, ser professor de biologia/ciências na EJA, demanda compreender que a modalidade na qual esse professor exerce sua profissão passa por enfrentamentos da ordem de políticas públicas educacionais.

Por esse ângulo, a discussão da EJA na relação com a escola, organizada a partir do fortalecimento do Estado liberal e do capitalismo, engendra um projeto formativo em que a formação para mão de obra é capital, por conseguinte, uma concepção utilitarista de educação fora traçada (MACHADO, 2009). Essa autora destaca, em sua discussão, as políticas de implementação da escolarização de pessoas jovens e adultas no contexto brasileiro pós Lei no 9.394/96, destacando principalmente o contraditório existente entre a formulação de políticas e o financiamento para implementação; demanda permanente de escolarização e programas/ações pontuais.

A formulação de políticas públicas educacionais impacta o cotidiano da sala de aula (MACHADO; RODRIGUES, 2014), portanto, é essencial que se tenha conhecimento de seus condicionantes de formulação e concepções acerca das matérias que tratam (educação, EJA, perspectivas pedagógicas). Com esse posicionamento, as autoras analisam os impactos da Lei n 13.005/2014 (Plano Nacional de Educação 2014 - 2024) na relação com a prática pedagógica dos professores da EJA. A demanda por essa modalidade é real e os dados indicam a urgência da EJA para suprir a escolarização de brasileiros, que na faixa etária de 18 a 29 anos somam 15.268.965 jovens que não estão na escola ou que não concluíram a Educação Básica.

A respeito do Plano Nacional de Educação 2014 - 2024, Machado e Rodrigues (2014) criticam o caráter de atendimento provisório dado à EJA ("programas de correção de fluxo"), materializado na estratégia 8.1 e 8.2 da meta 8 , o que se coloca na contramão da consolidação de políticas públicas de Estado pensadas para essa modalidade. A garantia de acesso gratuito à certificação de conclusão do ensino fundamental e médio é a estratégia 8.3. Sobre isso, as mesmas autoras apresentam a preocupação sobre as condições que os estados, municípios e Distrito Federal possuem para "regular e coibir a indústria de vendas dos certificados espalhada pelo País.” (MACHADO; RODRIGUES, 2014, p. 386). Percebe-se assim, que o caráter de atendimento provisório e o aligeiramento formativo do público da EJA ainda é um elemento de permanência presente no PNE vigente e se constitui um obstáculo a uma concepção de EJA que considere uma formação de qualidade socialmente referenciada.

Este breve apanhando explicitou as determinações a serem consideradas na organização do trabalho docente ao ensinar os conhecimentos sistematizados na modalidade. Defendemos a ideia que ensinar qualquer componente curricular na EJA pressupõe a tomada de consciência 
Seção: Teorias e Práticas Pedagógicas - Ensaio dissertativo

das determinações envolvidas no engendramento da necessidade histórica da educação de jovens e adultos no Brasil.

\section{A DEMARCAÇÃO DAS INTENCIONALIDADES FORMATIVAS PARA O ENSINO DE BIOLOGIA NA EJA}

O ensino de ciências se dá numa prática educativa institucionalizada (escola) que, por seu turno, é contraditória, pois a escola reproduz as relações sociais de produção e também se configura num espaço em que os conhecimentos científicos podem proporcionar o desenvolvimento humano aos educandos que passam por essa instituição. Por isso, entende-se que essa prática é alvo de interesses antagônicos em função da organização societal na qual a instituição escolar está inserida.

Faz-se necessário apresentar os aspectos pedagógicos que balizam a discussão do ensino de biologia na EJA para reiterar a concepção de que o ensino não se dá descolado de uma concepção de homem, sociedade, projeto formativo e instituição escolar. A ciência como atividade humana e o ensino de biologia que considere a totalidade no desenvolvimento dos conceitos do conhecimento biológico são aspectos a serem demarcados no ensino de biologia para a Educação de Jovens e Adultos.

Empregando os termos de Pinto (2010), a escola é o lugar para a transmissão dos "conhecimentos compendiados", havendo nesse processo uma intencionalidade, pois para esse autor, a educação está sempre "dirigida para". Portanto, o fazer pedagógico é intencional por natureza, sendo essa intencionalidade percebida ou não, mas que está alinhada a um projeto formativo posto. Nesse sentido, faz-se necessário compreender essas determinações para melhor localizar o ensino de biologia na EJA, considerando "o que" ensinar, "para que fins". Isso diz respeito ao aspecto político que perpassa o fazer pedagógico ao ensinar biologia na EJA.

Para Oliveira (1990b), a dimensão política no fazer pedagógico se faz presente por todo o tempo, mas a questão é que esse fazer sempre é visto em si mesmo e isso, por sua vez, marginaliza a dimensão política desse fazer. $\mathrm{O}$ ensino de biologia praticado com esse viés político demanda maior clareza das finalidades desse ensino por parte de quem ensina. Um viés político no ensino do conhecimento biológico, humaniza os indivíduos que estão inseridos na modalidade EJA? Pensando nessa questão, é que se defende, embora ainda num momento de reflexão e construção teórica, um ensino de biologia que considere as especificidades da EJA, considerando a dimensão ontológica da atividade científica e do desenvolvimento humano que os conhecimentos científicos podem proporcionar. 
Numa abordagem que consideraria os aspectos ontológicos que perpassam a atividade humana, o desenvolvimento dos conceitos científicos da biologia e o seu ensino consideraria "o quanto o gênero humano conseguiu se desenvolver ao longo do processo histórico de sua objetivação.” (DUARTE, 2009, p.11). Em abordagem semelhante, para Oliveira (1990a), compreender a ciência como atividade humana amplia a compreensão que a atividade científica se dá face às necessidades humanas, pois estas demandam respostas e geram o desenvolvimento do conhecimento humano. Ainda para essa autora, "a vida é o ponto de partida e de chegada de toda atividade e conhecimento do homem, desde as formas mais simples de criação e reprodução da realidade até as formas mais elaboradas do conhecimento como a ciência e a arte" (p.91).

O conhecimento objetivado torna-se elemento de apropriação. Na escola, a biologia poderia ser ensinada considerando a dinâmica da objetivação-apropriação que possibilitaria por sua vez, compreender a relação do homem com a natureza para além dos aspectos que a imediaticidade proporciona, mas que estabelece uma relação com a natureza para transformála, como nas palavras de Duarte (2013), em natureza humanizada. Com o aporte da compreensão sobre objetivação-apropriação envolvida na construção do conhecimento científico, assenta-se a perspectiva ontológica do homem enquanto um ser social. Ao considerar essa compreensão no ensino dos conceitos do conhecimento biológico, a história de sua produção (objetivação humana) e o próprio homem não seriam desconsiderados no ensino da biologia. O trabalho educativo ao se ensinar biologia sob essa ótica é direcionado por um fundamento ontológico, pois considera a dialética objetivação-apropriação presente na construção do conhecimento científico.

A discussão do ensino de biologia na EJA neste ensaio adota como matriz teórica a Pedagogia Histórico-Crítica, pois essa teoria permite compreender a natureza da educação de forma a considerar as "complexas mediações pelas quais se dá a sua inserção contraditória na sociedade capitalista." (SAVIANI, 2012, p.31). A natureza contraditória da educação já foi destacada no primeiro tópico, porém tratando especificamente o ensino de biologia, o saber escolar que abrange esse conhecimento tem que ser apresentado como instrumento de luta para a prática social. Entende-se que o ensino de biologia na EJA tem que estar socialmente referenciado face à organização societal vigente.

Entende-se que a pertinência de discutir o ensino de biologia na EJA considerando a Pedagogia Histórico-Crítica se dá em função do lugar e papel que o saber elaborado (ciência) possui nessa teoria, quando considerado a inserção do conhecimento científico na escola pelo viés do par dialético objetivação-apropriação enquanto um elemento de humanização do 
homem. A humanização se dá pela apropriação dos conhecimentos de distintas naturezas produzidos pelo homem (SAVIANI, 2013). Nas palavras desse autor, ao considerar a educação escolar, o trabalho educativo deve primar pelo saber objetivo historicamente produzido. Mas não se trata de um saber espontâneo, mas sim, o sistematizado. A partir desse apontamento, compreende-se que a ciência é uma atividade humana que objetiva a realidade e resulta um "conhecimento sistematizado, construído, avaliado e validado intersubjetivamente e objetivamente a partir de valores e regras compartilhados em determinados contextos históricos." (NASCIMENTO-JR; SOUZA; CARNEIRO, 2011, p.226).

O trabalho educativo na Pedagogia Histórico-Crítica (PHC) tem por finalidade, conforme aponta Saviani (2013, p.6), "produzir, direta e intencionalmente, em cada indivíduo singular, a humanidade que é produzida histórica e coletivamente pelo conjunto dos homens". Isso por sua vez, como indica o autor, delineia as tarefas da PHC que se vinculam a três pontos:

\footnotetext{
Identificação das formas mais desenvolvidas em que se expressa o saber objetivo produzido historicamente, reconhecendo as condições de sua produção e compreendendo as suas principais manifestações, bem como as tendências atuais de transformação.

Conversão do saber objetivo em saber escolar, de modo que se torne assimilável pelos alunos nos espaços e tempos escolares.

Provimento dos meios necessários para que os alunos não apenas assimilem o saber objetivo enquanto resultado, mas apreendam o processo de sua produção, bem como as tendências de sua transformação. (SAVIANI, 2013, p.8-9)
}

Essas três tarefas indicam a necessidade de se rever o ensino de biologia. No recorte deste ensaio, a primeira tarefa explicita o desafio para o ensino de biologia em elencar os conceitos elementares dessa ciência a serem trabalhados com os educandos da EJA, pois o ensino que visa o desenvolvimento humano e o pensamento por conceitos não implica esgotar em quantidade a apresentação dos conceitos do conhecimento biológico.

A ciência biológica se organiza em torno de teorias fundantes (Teoria Celular, Teoria da Homeostase, Teoria da Herança, Teoria da Evolução e Teoria do Ecossistema) (NASCIMENTO-JR; SOUZA; CARNEIRO, 2011). Face a isso, o trabalho pedagógico relacionado ao ensino de ciências na EJA deveria voltar-se à escolha de conceitos essenciais das teorias que fundamentam a biologia de maneira a proporcionar aos educandos a compreensão do desenvolvimento histórico dos conceitos trabalhados, bem como os seus fundamentos. A partir desse apontamento, seria possibilitado aos educandos a compreensão do processo pelo qual o homem interfere na natureza para a produção de sua própria existência (SAVIANI, 2013), considerando o recorte do ensino de biologia.

A escolha dos conceitos essenciais da biologia, mencionada no parágrafo anterior, não implica em redução e/ou marginalização dos conceitos da biologia. Nessa perspectiva, entende- 
se que se instalaria a segunda tarefa da Pedagogia Histórico-Crítica como um fundamento teórico-pedagógico para o ensino de biologia na EJA, ou seja, converter o saber objetivo em saber escolar. $O$ ensino de biologia na EJA não coincide com a atividade científica dessa ciência, pois o papel da escola está diretamente vinculado à socialização dos instrumentos (conceitos científicos) advindos da biologia que permitem ao homem objetivações e apropriações da realidade sempre em níveis mais complexos. Na perspectiva da educação escolar, o desenvolvimento humano passa pela apropriação desses instrumentos.

A terceira tarefa da Pedagogia Histórico-Crítica é a que coloca o desafio da ruptura de modelos hegemônicos do processo de ensino que centraliza a apresentação dos conceitos científicos descolados dos processos que possibilitaram a sua construção. Pensar o ensino de biologia sob a perspectiva dessa tarefa remete ao pensamento de Nascimento-Jr, Souza e Carneiro (2011) que apontam a necessidade de se estabelecer uma prática pedagógica dialética que considere um ensino sobre a ciência (processo) e um ensino de ciências (produto) em que não haja a ênfase de um em detrimento do outro.

A atividade científica é uma atividade intencional que envolve as determinantes de uma época. Posto isso, na transposição do conhecimento científico para o saber escolar, o foco não deveria centrar-se apenas nos produtos desse processo, entendidos aqui como os conceitos científicos da biologia. O processo de produção do conhecimento científico na relação com os conceitos produzidos ampliaria a compreensão que a atividade científica é humana, intencional, histórica e, portanto, se transforma. Duarte (2013) afirma que a objetivação e apropriação se dão em condições socialmente determinadas e, portanto, se transformam. É uma acepção a ser considerada no ensino de biologia na EJA de maneira a romper com a centralidade dada à apresentação dos conceitos científicos em que estes se constituem no ponto de partida e de chegada, o que corrobora concepções distorcidas/ingênuas da atividade científica.

O delineamento teórico realizado até o momento, permite estabelecer considerações sobre o ensino do conhecimento biológico praticado na EJA a partir das pesquisas realizadas sobre o ensino de biologia e das práticas de ensino desenvolvidas em escolas de EJA (PARANHOS, 2017). É necessário desenvolver a compreensão que ensinar biologia na EJA demanda recorrer aos aspectos históricos da educação de adultos no Brasil.

Ainda há questões a serem vencidas, principalmente as que atrelam as especificidades da modalidade aos aspectos metodológicos do ensinar. O ensino de ciências na EJA demanda marcar as concepções de educação, homem e sociedade que respaldam o ensino de ciências nessa modalidade de educação, para que não se caia nas transposições das formas de ensinar ciências postas para o Ensino Fundamental e Médio (PARANHOS; FIRMINO, 2013). 


\section{APONTAMENTOS PARA A EDUCAÇÃO ESCOLAR E O ENSINO DE CIÊNCIAS NA EJA}

Este ensaio colocou em relevo a necessidade histórica da modalidade EJA enquanto uma demanda real no cenário educacional brasileiro, seja pelos aspectos da alfabetização ou pela conclusão da educação básica por parte de milhares de brasileiros que não dominam a leitura/escrita ou que não concluíram a educação básica. A discussão presente neste ensaio se instala nas questões que perpassam a formação que o conhecimento científico (biológico) pode proporcionar aos educandos, na perspectiva de promover o desenvolvimento humano. Para tanto, é necessário pensar a EJA em sua materialidade, de maneira a ressignificar o discurso assistencialista que ainda tangencia a modalidade e que pode comprometer a sua "especificidade", desconsiderando a sua essência (público), tornando-a um "jargão pedagógico" esvaziado da intencionalidade político-formativa que o desenvolvimento humano requer.

O ensino na educação de jovens e adultos, seja ele de qualquer componente curricular, demanda considerar a relação entre o público da modalidade (essência da especificidade da EJA) e o projeto formativo posto para a escola no seu atual formato organizacional. Desconsiderar essa relação é alienar-se do processo de pensar as especificidades do ensino de biologia para os educandos da EJA, corroborando, assim, o que está posto para a escola na atual organização social.

Sobre as concepções de EJA está travada uma discussão que resiste à compreensão da modalidade, e permanece ainda atrelada ao entendimento ligado à suplência, o que se desdobra em processos formativos aligeirados e fragiliza a ideia que o público da EJA está constituído por sujeitos de direito e não por um público que necessita de processos de recuperação do "tempo perdido".

É necessário ainda marcar que a EJA é uma modalidade de Educação que possui desdobramentos para os aspectos do ensino. É um aspecto que da perspectiva conceitual possui uma diferença, pois compreende-se que pensá-la enquanto uma modalidade de educação requer atentar-se para: a) sua inserção no cenário educacional brasileiro; b) sua trajetória de luta no campo das políticas públicas; c) seus enfrentamentos para se fazer oferecida nas diferentes esferas da administração pública (municipal, estadual e federal); d) os processos formativos de maneira ampla em que o desenvolvimento humano esteja no alvo, em detrimento de outras perspectivas formativas mais utilitaristas/funcionalistas. Enquanto modalidade, esses aspectos 
devem ser considerados nas questões do ensino, porém sem se restringir a eles, pois assim, dicotomizaria-se o conteúdo da forma.

Pelas características da modalidade e, principalmente, às ligadas ao seu público, a EJA explicita a todo momento os limites, seja para os aspectos organizacionais ou didáticopedagógicos do que se encontra na escola e ao que é oferecido para essa modalidade. Não que o que está posto deva ser desconsiderado em sua totalidade, mas justamente pelo fato da EJA se colocar como um modo próprio de ser e de existir, a escola e seus processos devem estar, ao menos, abertos a reorganizações que a modalidade requer. É necessário ter maior clareza sobre a instituição em que a EJA se insere (escola e seu projeto formativo). Echeverría em sua tese, afirma que

A escola é, certamente, uma instituição que deveria mudar, mas é com ela, como ela existe e, a partir do que ela é, que se tem de trabalhar, até porque entre as inúmeras contradições que nela se desenvolvem, se apresentam brechas para um trabalho progressista, questionador e, também, transformador (ECHEVERRÍA, 1993, p.10).

Com isso, a autora convida a pensar sobre as determinações da escola no seio da vigente organização social, para localizar as práticas intencionais que nela se dão com vistas, inclusive, à transformá-la.

A EJA, por sua especificidade, já coloca os limites para a organização da escola e seu projeto formativo. A instituição escolar apresenta uma contradição que lhe é peculiar. Por um lado, a educação que essa instituição oferece está marcada em leis, o que confere a obrigatoriedade da escolarização a uma faixa etária e, por outro, escolarizar-se se dá em meio a mecanismos de exclusão social (TUNES; PEDROZA, 2011). De acordo com essas autoras, na sociedade capitalista o ensino institucionalizado possui marcas da lógica empresarial em que os conhecimentos são comercializados e o educando se torna um objeto a ser consumido. Os processos de exclusão social não se encontram separados da instituição escolar, sendo necessário ter cautela com análises que supervalorizam a exclusão escolar sem estabelecer as devidas relações com a totalidade social. A escola não é uma ilha e não está imune às relações sociais de produção capitalista. Nesse sentido, Tunes e Pedroza (2011, p.20) dizem que "a vida não pára e perde as suas referências dentro do espaço escolar; muito pelo contrário, a escola é sociedade".

Tunes e Pedroza (2011) afirmam que o desafio que se coloca à instituição escolar não é o de incluir os excluídos, mas o de considerar a diversidade enquanto uma condição humana a ser incluída na escola. Para a EJA isso possui total pertinência e coloca um desafio para o ensino de biologia nessa modalidade, pois não se trata apenas de pensar na inclusão de sujeitos que 
tiveram o direito a educação negado em determinado momento histórico de suas vidas. A questão é garantir esse direito e ao mesmo tempo incluir na instituição escolar a diversidade característica desse público e ainda desvelar modos de como o conhecimento biológico poderia fornecer elementos para que esses educandos compreendessem as suas inserções na realidade. Se afastar dessa postura e/ou não considerar esses aspectos, ensinar biologia na EJA se tornará uma atividade que corroborará com o que aponta Tunes e Pedroza (2011, p.26) sobre a perda “[...] de tempo com a inclusão dos "diferentes" dentro da fabricação de iguais".

Dessa maneira, quando consideradas as propostas pedagógicas postas para a Educação de Jovens Adultos, há a necessidade de desenvolver um olhar mais acurado para a formação veiculada por estas, pois como destaca Lombardi (2011, p.239), estamos num tempo em que é vivenciada uma defesa "apologética do particular, do fragmentário, do microscópio, da ideia, da subjetividade e da irracionalidade, não temos motivo algum para ficarmos na retaguarda". Para o autor, é necessário nos munir de teorias que possibilitem realizar análises críticas que se pautem na materialidade, na totalidade histórico-social, na objetividade e na racionalidade revolucionária que perpassam o fenômeno educativo.

Rossi (1978) afirma em sua obra que não se reforma a educação com mera introdução de técnicas didáticas, bem como, não se transforma o sentido da escola capitalista com o simples preenchimento de um aparato tecnológico. E aqui reforça-se a ideia de que a EJA está revestida do discurso da especificidade que, nas pesquisas sobre o ensino de biologia, parece se inclinar fortemente para o emprego de metodologias de ensino. Isso é uma mera questão do aparente, pois em que medida, ter como ponto de partida o aspecto metodológico de ensinar biologia marca uma concepção de homem e mundo diferentes dos preceitos capitalistas?

A Educação de Jovens e Adultos é voltada para um público marginalizado do direito ao acesso à educação. O início e/ou a continuação do processo de escolarização pode manter essa condição de marginalizados caso, os projetos formativos das diferentes propostas pedagógicas para a modalidade em questão não marquem qual é concepção de educação posta para o público da EJA e o desdobramento formativo advindo dessa concepção.

Não estabelecer as devidas relações com a totalidade na qual a escola se insere e, sobretudo, promover a ilusão de que a exclusão social é um desdobramento direto da não escolarização, é corroborar também que por ela se processa a ascensão social (TUNES; PEDROZA, 2011). Portanto, no contexto da Educação de Jovens e Adultos, compreende-se que a escola, via os conhecimentos que nela são socializados, deveria proporcionar uma leitura mais ampla e verticalizada da realidade em que os educandos da EJA estão inseridos, inclusive, para compreender as determinações envolvidas nos processos de marginalização que muitos 
vivenciam. Caso isso não ocorra, entende-se que ocorrerá a marginalização reiterada e institucionalizada [grifo nosso] dos educandos que pela escola passam.

Reiterada porque a marginalização se renova de maneira ressignificada pelo fato do educando não obter uma formação que possibilite uma prática social emancipadora e que se desdobra no impedimento de realizar uma leitura mais ampliada da realidade a partir dos conceitos científicos. Reiterada porque se não houver a ruptura no formato da apresentação dos conceitos científicos (biológicos) enquanto produtos, desconsiderando os processos que permitiram as suas formulações, haverá prejuízos à compreensão que a ciência é uma atividade humana intencional e está inserida nas relações contraditórias de classe presentes na atual organização societal. Essa mesma marginalização se torna institucionalizada pois o projeto formativo da escola, em suas entrelinhas, corrobora a manutenção das diferenças de classes e chancela os aparatos ideológicos que inculcam nos educandos os preceitos do capital humano e a possibilidade de ascensão social.

\section{REFERÊNCIAS}

ALVES, T. et al. Jovens e adultos não escolarizados - uma multidão de invisíveis. In: OLIVEIRA, E. C.; CEZARINO, K. R. A., et al (Ed.). Educação de jovens e adultos: trabalho e formação humana. São Carlos: Pedro \& João Editores, 2014. p.167-190.

ARROYO, M. A educação de jovens e adultos em tempos de exclusão. In: Construção coletiva: contribuições à educação de jovens e adultos. Brasília: UNESCO, MEC, RAAAB, 2005. p.221-241.

CARRANO, P. C. R. Identidades juvenis e escola. In: Construção coletiva: contribuições à educação de jovens e adultos. Brasília: UNESCO, MEC, RAAAB, 2005. p.153-164.

CATELLI-JR, R.; ESCOURA, M. Sujeitos da diversidade: a agenda LGBT na educação de jovens e adultos. Olh@res, São Paulo, v.4, n.1, p.226-245, maio, 2016.

CONAE 2010. Documento final. Construindo o Sistema Nacional Articulado de

Educação: o Plano Nacional de Educação, Diretrizes e Estratégias de Ação. Brasília: MEC, 2010.

CURY, C. R. J. Educação e contradição: elementos metodológicos para uma teoria crítica do fenômeno educativo. 7. ed. São Paulo: Cortez, 2000.

DUARTE, N. A individualidade para si: contribuição a uma teoria histórico-crítica da formação do indivíduo. 3. ed. Campinas: Autores Associados, 2013.

ECHEVERRÍA, A. R. Dimensão empírico-teórica no processo de ensino-aprendizagem do conceito de soluções no ensino médio. 1993. Tese (Doutorado). Faculdade de Educação, Universidade Estadual de Campinas, Campinas, SP.

ENGUITA, M. F. A face oculta da escola: educação e trabalho no capitalismo. Porto Alegre: Artes Médicas, 1989. 
FRIGOTTO, G. A produtividade da escola improdutiva: um (re)exame das relações entre educação e estrutura econômico-social capitalista. 9. ed. São Paulo: Cortez, 2010a.

FRIGOTTO, G. Educação e a crise do capitalismo real. 6. ed. São Paulo: Cortez, 2010b.

FURINI, D. R. M.; DURAND, O. C. D. S.; SANTOS, P. D. Sujeitos da educação de jovens e adultos, espaços e múltiplos saberes. In: LAFFIN, M. H. L. F. (org.). Educação de jovens e adultos: educação na diversidade. Florianópolis: Universidade Federal de Santa Catarina, 2011. p.160-244.

HOBSBAWM, E. J. A era das revoluções, 1780 - 1848. 34. ed. Rio de Janeiro: Paz e Terra, 2014.

HOBSBAWM, E. J. A era do capital, 1848 - 1875. 23. ed. São Paulo: Paz e Terra, 2015a.

HOBSBAWM, E. J. A era dos impérios, 1875 - 1914. 19. ed. Rio de Janeiro: Paz e Terra, 2015 b.

LOMBARDI, J. C. Educação e ensino na obra de Marx e Engels. Campinas: Editora Alínea, 2011.

MACHADO, M. M. A educação de jovens e adultos no Brasil pós-Lei no 9.394/96: a possibilidade de constituir-se como política pública. Em Aberto, Brasília, v. 22, n. 82, p.1739, 2009.

MACHADO, M. M. Quando a obrigatoriedade afirma e nega o direito à educação. Retratos da Escola, Brasília, v. 4, n. 7, p. 245-258, jul./dez., 2010.

MACHADO, M. M.; RODRIGUES, M. E. C. A EJA na próxima década e a prática pedagógica do docente. Retratos da Escola, Brasília, v. 8, n. 15, p. 383-395, jul./dez., 2014.

MARX, K. Prefácio a Para a crítica da Economia Política. In: NETTO, J. P. (org.). O leitor de Marx. Rio de Janeiro, RJ: Civilização Brasileira, 2012. p.267-273.

MÉSZÁROS, I. A educação para além do capital. 2. ed. São Paulo: Boitempo, 2008.

NASCIMENTO-JR, A. F.; SOUZA, D. C.; CARNEIRO, M. C. O conhecimento biológico nos documentos curriculares nacionais do ensino médio: uma análise histórico-filosófica a partir dos estatutos da biologia. Investigações em Ensino de Ciências, Porto Alegre, v. 16, n. 2, p. 223-243, 2011.

OLIVEIRA, B. A prática social global como ponto de partida e de chegada da prática educativa. In: OLIVEIRA, B.; DUARTE, N. (org.). Socialização do saber escolar. São Paulo: Cortez, 1990b. p.91-104.

OLIVEIRA, B. A socialização do saber sistematizado e a dimensão política da prática especificamente pedagógica. In: OLIVEIRA, B..; DUARTE, N. (org.). Socialização do saber escolar. São Paulo: Cortez, 1990a. p.11-46.

PARANHOS, R. D. Ensino de Biologia na Educação de Jovens e Adultos: o pensamento político-pedagógico da produção científica brasileira. Brasília - DF, 2017. 229f. Tese (Doutorado - Doutorado em Educação). Faculdade de Educação, Universidade de Brasília.

PARANHOS, R. D.; FIRMINO, S. G. "Professor, onde eu encontro células no meu corpo?": as necessidades formativas do professor de biologia para atuar na EJA. In: GUIMARÃES, S. S. M. et al (org.). Formação de professores de biologia: os desa(fios) da trama. São Carlos: Pedro \& João Editores, 2013. p.87-106.

PINTO, A. V. Sete lições sobre educação de adultos. 16. ed. São Paulo: Cortez, 2010. 
ROSSI, W. G. Capitalismo e educação: contribuição ao estudo crítico da economia da educação capitalista. São Paulo: Cortez \& Moraes, 1978.

SARTORI, A. Legislação, políticas públicas e concepções de educação de jovens e adultos. In: LAFFIN, M. H. L. F. (org.). Educação de jovens e adultos e educação na diversidade. Florianópolis: Universidade Federal de Santa Catarina, 2011. p.12-125.

SAVIANI, D. Escola e Democracia. 42. ed. Campinas: Autores Associados, 2012.

SAVIANI, D. Pedagogia Histórico-Crítica. 11. ed. Campinas: Autores Associados, 2013.

SOUTO, R. B. Prática docente e currículo na educação de jovens e adultos. In: LAFFIN, M. H. L. F. (org.). Educação de jovens e adultos e educação na diversidade. Florianópolis: Universidade Federal de Santa Catarina, 2011. p.280-311.

TUNES, E; PEDROZA, L. P. O silêncio ou a profanação do outro. In: TUNES, E. (org.). Sem escola, sem documento. Rio de Janeiro: E-papers, 2011. p.15-30.

ZORZAL, E. S.; MIRANDA, G.; RODRIGUES, H. J. A. Formação e diversidade dos sujeitos no campo da EJA: a prática de pensar a prática. In: OLIVEIRA, E. C.; CEZARINO, K. R. A., et al (org.). Educação de Jovens e Adultos: trabalho e formação humana. São Carlos: Pedro \& João Editores, 2014. p.21-44. 